\title{
TUBARÕES E RAIAS COMO CAPTURA INCIDENTAL NA PESCA ARTESANAL DO LITORAL DO PARANÁ: CONDIÇÃO REPRODUTIVA E VARIAÇÕES SAZONAIS EM COMPOSICGÃO E ABUNDÂNCIA
}

\author{
Sharks and rays as incidental catch of artisanal fishing activity in \\ Southern Brazil: reproductive attributes and seasonal changes in \\ composition and abundance
}

\author{
Paulo de Tarso da Cunha Chaves ${ }^{1}$, Maurício Pinto de Almeida ${ }^{2}$, Matheus Platner ${ }^{3}$ \\ ${ }_{1}^{1}$ Professor do Departamento de Zoologia (DZoo/UFPR), Universidade Federal do Paraná. E-mail: ptchaves@ufpr.br \\ ${ }^{2}$ Pós-doutorando no Programa de Pós-Graduação em Zoologia (DZoo/UFPR). E-mail: maupalms@gmail.com \\ ${ }^{3}$ Estudante de Ciências Biológicas no DZoo/UFPR. E-mail: matheusplatner2@gmail.com
}

\begin{abstract}
RESUMO
Monitoraram-se os desembarques de elasmobrânquios no litoral do Paraná nos anos 2009 e 2010. Descrevem-se atributos de frota e petrechos empregados. As espécies foram caracterizadas quanto ao tamanho dos indivíduos e à condição reprodutiva. Acessaram-se 4.941 indivíduos, 51 \% tubarões e $49 \%$ raias. Foram desembarcados inteiros $82 \%$ dos indivíduos, 3,68 t de tubarões e 2,35 t de raias. Identificaram-se 14 espécies de tubarões, peso médio de 1,46 kg (0,067-16,0 kg; DP =3,83), predominando em número Rhizoprionodon lalandii e Sphyrna zygaena. Os tubarões foram mais capturados na primavera/verão, com maior frequência de neonatos ou imaturos. Registraram-se 12 espécies de raias, peso médio de 0,971 kg $(0,394-10,0 \mathrm{~kg}$; DP = 2,80), predominando em número Zapteryx brevirostris e Pseudobatos percellens. As raias foram mais capturadas no outono, em pescarias dirigidas a camarões e pequenos teleósteos, com maior frequência de imaturas ou maduras. Onze das 26 espécies são classificadas como vulneráveis, em perigo ou criticamente ameaçadas. Para fins de conservação, recomendam-se ações educativas pró-descarte de: animais vivos - neonatos em geral, Narcine brasiliensis no arrasto camaroeiro, e jovens e adultos de espécies com captura proibida; e priorização à proteção de Carcharias taurus, P. percellens acompanhante da pesca de linguado, e jovens de Squatina sp., cujos adultos são alvo em redes de emalhe.
\end{abstract}

Palavras-chave: reprodução, neonatos, arrasto, captura incidental, Rhizoprionodon lalandii, Sphyrna zygaena, Zapteryx brevirostris.

Recebido em: 18/12/2018

Aprovado em: 9/11/2019

Publicado online em: 20/3/2020 


\section{ABSTRACT}

Landings of elasmobranchs at Parana coast, Southern Brazil, were monitored during two years, 2009 and 2010. Attributes of fleet and fishing gears were described, as well as species composition, body length and reproductive status of individuals. A total of 4,941 sharks (51\%) and rays $(49 \%)$ was accessed. Part of them was eviscerated, but $82 \%$ were landed intact, corresponding to $3.68 \mathrm{t}$ of sharks and $2.35 \mathrm{t}$ of rays. Fourteen species of shark were recognized, mean weight $1.46 \mathrm{~kg}$ (0.067-16.0 kg; SD = 3.83), mostly Rhizoprionodon lalandii and Sphyrna zygaena, Shark landings were higher in spring/summer, taking part in teleost fisheries. Twelve species of rays were recognized, mean weight $0.97 \mathrm{~kg}(0.394-10.0 \mathrm{~kg}$; $S D=2.80)$, being Zapteryx brevirostris and Pseudobatos percellens the most numerous. Ray catches were higher in autumn, in both juvenile and adult stages, in fisheries targeting shrimps and small teleosts. Eleven out 26 elasmobranch species are classified in Vulnerable, Endangered or Critically endangered conservation status. Aiming conservation, two main actions are recommended: first, educative campaigns to promote releasing of: live individuals, neonates in general, Narcine brasiliensis in shrimp trawling, and young and adults of species with catches forbidden; second, protection of Carcharias taurus, P. percellens as incidental catch in flatfish fisheries, and youngs of Squatina sp., a species which adults are targeted in gillnet fisheries.

Keywords: reproduction, neonates, trawling, incidental catches, Rhizoprionodon lalandii, Sphyrna zygaena, Zapteryx brevirostris.

\section{INTRODUÇÃO}

Elasmobrânquios são frequentemente capturados na condição de acompanhantes dos recursos-alvo, peixes ósseos (Musick \& Bonfil, 2004; Nunes et al., 2005; Costa \& Chaves, 2006). É um grupo naturalmente sensível à pesca, pois reúne alta longevidade, maturação sexual tardia, longos períodos de gestação, crescimento lento e outras estratégias de vida de animais com tendência K-estrategista (Hoenig \& Gruber, 1990). Estoques que entraram em colapso devido à atividade pesqueira são conhecidos mundialmente (Camhi et al., 1998; Casey \& Myers, 1998; Baum \& Myers, 2004; Musick \& Bonfil, 2004; Luiz \& Edwards, 2011; Barausse et al., 2014). No estado do Paraná, a captura de Carcharias taurus (mangona) até os anos 1990 era frequente, com desembarques medidos em toneladas; entretanto, nos anos 2000, restringe-se a eventos esporádicos, com poucos exemplares (Bornatowski et al., 2009). Na costa do Maranhão, onde uma variedade de elasmobrânquios é capturada incidentalmente, há pressão sobre espécies ameaçadas de extinção, como Carcharhinus porosus, Ginglymostoma cirratum e Sphyrna spp., que, mesmo na ilegalidade, são comercializadas (Martins et al., 2018). Ademais, destaca-se possível extinção de espécie endêmica, Isogomphodon oxyrhynchus, fruto de sobrepesca, aliada à baixa fecundidade e população já diminuta (Lessa et al., 2016).

Como fonte de dados populacionais e sobre os efeitos da pesca na densidade dos estoques, recomenda-se o acompanhamento de desembarques pesqueiros (Shepherd, 1984). No estado do Paraná, apesar de a costa ser relativamente pequena $(90 \mathrm{~km})$, estatísticas de captura de elasmobrânquios inexistem. A pesca é de pequena escala e os desembarques provêm da plataforma continental interna. Somando-se os atributos de pesca em 
águas rasas, comuns berçários de elasmobrânquios, aos atributos naturais das espécies do grupo, a pesca de elasmobrânquios assume na região condição delicada para a conservação do grupo.

Matinhos é o local de maior desembarque de pescados no litoral do Paraná. Na plataforma rasa praticam-se a pesca profissional, que utiliza redes de vários tipos, além de anzóis e armadilhas, e a amadora, com vara e anzol. Próximo à costa, a pesca profissional usa principalmente uma arte ativa - as redes de arrasto camaroeiro - e outra passiva - as redes de emalhe (Chaves \& Robert, 2003; Robert \& Chaves, 2006). As capturas são multiespecíficas, com forte ocorrência de captura incidental (Chaves \& Silva, 2019). O presente estudo descreve a pesca de elasmobrânquios realizada pela frota de Matinhos, caracterizando os petrechos utilizados, a composição das capturas e suas variações sazonais.

\section{MATERIAL E MÉTODOS}

Contagem das canoas sediadas na Praia Central de Matinhos e sua caracterização quanto ao porte e motorização foram realizadas no início do trabalho de campo, outono de 2009, utilizando-se critérios apresentados por Robert e Chaves (2006).

Os dados de desembarque foram obtidos de junho de 2009 a maio de 2010 em 14 dias por mês, divididos em duas amostragens de sete dias consecutivos cada, exceto em dezembro e fevereiro, quando apenas uma amostragem de sete dias foi realizada. Assim, em 12 meses, o trabalho de campo totalizou 154 dias, sempre se estendendo do início da manhã ao final da tarde. Nesses dias, foram considerados todos os elasmobrânquios desembarcados, de $100 \%$ da frota atuante.

Nos desembarques, os pescadores informavam a procedência das capturas. No período de estudo, a frota atuou nas proximidades de Matinhos

Figura 1 - Localização de Matinhos, litoral do Paraná, onde foram monitorados os desembarques, e das ilhas Itacolomis e Currais, sítios de pesca na região.

e no entorno das Ilhas Itacolomis e Currais, entre 30 minutos e 3,5 horas de navegação a partir da praia de partida e desembarque (Figura 1). As pescarias mais próximas da costa, cerca de 30 minutos de navegação, visavam principalmente à captura de peixes de pequeno porte e camarões; e as mais distantes, peixes em geral. Ocasional mente houve capturas no litoral sul de São Paulo, Ilha de SupeFonte: adaptada de Lorenzi e Borzone (2009).




ragui, e norte de Santa Catarina, próximo a Itapoá. Consideraram-se desembarques "positivos" aqueles que traziam elasmobrânquios. Teste chi-quadrado de Pearson foi aplicado a pares de amostras para comparar a incidência de desembarques positivos entre meses consecutivos. Assumiu-se como hipótese nula o mês em análise ter percentual de desembarques positivos não diferente do mês anterior.

A identificação do material baseou-se em Hubbs e Ishiyama (1968), Figueiredo (1977), Castro (1983), Compagno (1984, 2005), Aguiar (1999) e Gadig (2001) e foi complementada por análise fotográfica realizada por especialistas na área. A quantificação da abundância considerou o estado em que os indivíduos eram desembarcados: inteiros ou eviscerados.

O tamanho de malha das redes refere-se à medida entre nós opostos e foi informado pelos pescadores no desembarque. $\mathrm{O}$ peso informado pelos pescadores correspondeu ao conjunto de peixes inteiros de mesma espécie, compartilhando caixa plástica utilizada no transbordo entre a canoa e o mercado. Informações sobre estágio de desenvolvimento basearam-se no grau de calcificação dos clásperes (machos) e na visualização do trato genital, além do tamanho corpóreo, levando à seguinte categorização: indivíduos neonatos, imaturos ou maduros (Conrath, 2004). Para distribuição sazonal dos dados, dezembro, janeiro e fevereiro foram considerados verão e, assim, sucessivamente.

\section{RESULTADOS}

No período de 2009 e 2010, a frota de Matinhos somava 39 embarcações assim distribuídas: 11 (28\%), uma das quais inativa, específicas para arrasto de camarão; 20 (51\%), uma das quais inativa, da modalidade "pesca mista" (camarões e/ou peixes), dependendo do preço dos produtos-alvo; e oito (21\%) direcionadas para peixes. Cinco eram de madeira; as demais, de fibra de vidro em sete moldes básicos diferenciados; todas possuíam geladeira, um compartimento para armazenagem de pescados em gelo. Para captura de camarões, as canoas eram equipadas com rede de arrasto e pranchas, ou portas, e guincho acoplado ao motor de propulsão; quando para peixes, com rede de emalhe e bandeiras de sinalização. A potência do motor variou de $8 \mathrm{hp}$ a MWM 160 turbinado, porém mais da metade era $18 \mathrm{hp}$.

As pescarias realizadas nas proximidades de Matinhos capturaram elasmobrânquios de pequeno porte e imaturos; aquelas realizadas ao redor das ilhas, em locais mais profundos e menos explorados, capturaram menos imaturos ou maduros e de maior porte. As áreas de pesca da frota de Matinhos são compartilhadas com frotas de outros locais e estados. O desembarque total registrado foi de 4.941 indivíduos. Da amostra, 2.508 (50,7\%) foram tubarões e $2.432(49,3 \%)$, raias. Do total, $4.045(81,9 \%)$ indivíduos foram desembarcados inteiros e 797 (16,1\%), eviscerados. Os demais 99 (2\%) foram alocados na categoria "sem informações", pois comercializados antes da observação, ou não cedidos pelos pescadores para visualização. Identificaram-se 26 espécies, 14 de tubarões e 12 de raias, das quais 11 integram listas de ameaçadas de extinção (Tabela I).

Tabela I - Tubarões e raias registrados no desembarque em Matinhos-PR entre junho de 2009 e maio de 2010

\begin{tabular}{|c|c|c|c|}
\hline & Família & Nome comum & Cat \\
\hline \multicolumn{4}{|l|}{ Tubarões } \\
\hline Alopias vulpinus & Alopiidae & raposa & VU \\
\hline Carcharhinus falciformis & Carcharhinidae & figo-branco & \\
\hline C. leucas & Carcharhinidae & cabeça-chata & \\
\hline
\end{tabular}


(continuação Tabela 1)

\begin{tabular}{|c|c|c|c|}
\hline & Família & Nome comum & Cat \\
\hline C. limbatus & Carcharhinidae & galha-preta & \\
\hline C.obscurus & Carcharhinidae & cabeça-chata & EN \\
\hline C. porosus & Carcharhinidae & azeitero & $\mathrm{CR}$ \\
\hline Carcharias taurus & Carcharhinidae & mangona & $\mathrm{CR}$ \\
\hline Galeocerdo cuvier & Carcharhinidae & tigre, tintureira & \\
\hline Isurus oxyrhynchus & Lamnidae & anequim, mako & \\
\hline Rhizoprionodon lalandii & Carcharhinidae & frango, rola-rola & \\
\hline R. porosus & Carcharhinidae & frango, rola-rola & \\
\hline Sphyrna lewini & Sphyrnidae & martelo, cambeva & $\mathrm{CR}$ \\
\hline S. zygaena & Sphyrnidae & martelo, cambeva & $\mathrm{CR}$ \\
\hline Squatina guggenheim & Squatinidae & anjo & $\mathrm{CR}$ \\
\hline \multicolumn{4}{|l|}{ Raias } \\
\hline Aetobatus narinari & Aetobatidae & chita & \\
\hline Atlantoraja castelnaui & Arhynchobatidae & emplastro & EN \\
\hline Dasyatis hypostigma & Dasyatidae & manteiga & \\
\hline Gymnura altavela & Gymnuridae & jereva & $\mathrm{CR}$ \\
\hline Hypanus guttatus & Dasyatidae & chicote & \\
\hline Myliobatis goodei & Myliobatidae & morcego & $\mathrm{CR}$ \\
\hline Narcine brasiliensis & Narcinidae & treme-treme & \\
\hline Pseudobatos percellens & Rhinobatidae & viola & \\
\hline Pteroplatytrygon violacea & Dasyatidae & manteiga & \\
\hline Rhinoptera bonasus & Myliobatidae & cachorro & \\
\hline Rioraja agazissii & Arhynchobatidae & emplastro & \\
\hline Zapteryx brevirostris & Trygonorrhinidae & bandolim & VU \\
\hline
\end{tabular}

Nota: Cat: categoria segundo Portarias MMA 445/2014 e 163/2015. VU: vulnerável; EN: em perigo; CR: criticamente em perigo.

Registraram-se, ainda, quatro gêneros sem identificação específica, dois de tubarões - Carcharhinus e Rhizoprionodon - e dois de raias - Dasyatis e Rhinoptera -, indivíduos desembarcados sem cabeça e/ou cortados em partes. Dos nove indivíduos de Rhizoprionodon sp., quatro pareceram ser R. lalandii, por possuir cabeça estreita e focinho afilado, pequeno porte e ápice das nadadeiras peitorais aparentemente não ultrapassando a metade da largura da base da nadadeira dorsal quando comprimida junto ao corpo. Os outros cinco foram desembarcados em filé, impossibilitando identificação precisa, mas possuíam crista pré-anal evidente. Três indivíduos de Dasyatidae eram provavelmente $H$. guttatus, pela coloração dorsal castanho-clara, disco aparentemente em forma de diamante com focinho curto, nadadeiras pélvicas de forma triangular e com margens arredondadas. Os 11 indivíduos de Rhinoptera sp. foram desembarcados cortados, sem couro e sem cabeça. Dos 50 indivíduos de Carcharhinus sp., 15 foram desembarcados sem filé, reconhecidos como tal pelo formato do corpo e pela ausência de crista pré-anal. Do restante, 35 indivíduos, oito possuíam o ápice das nadadeiras peitorais escuras, não possuíam crista dérmica longitudinal entre as nadadeiras dorsais, possuíam o comprimento da primeira fenda branquial com até 2,5 vezes o diâmetro horizontal do olho, caracterizando-se morfologicamente como C. limbatus; e os demais 27 geraram identificações específicas conflitantes.

No cômputo geral, os mais registrados nos desembarques foram os tubarões $R$. lalandii e S. zygaena (Tabela II) e as raias Z. brevirostris e R. percellens (Tabela III). 
Tabela II - Número de tubarões registrados mensalmente nos desembarques da rota em Matinhos-PR de junho de 2009 a maio de 2010

\begin{tabular}{lrrrrrrrrrrrrrr}
\hline & Jun. & Jul. & Ago. & Set. & Out. & Nov. & Dez. & Jan. & Fev. & Mar. & Abr. Maio & Total \\
\hline Alopias vulpinus & 0 & 0 & 1 & 0 & 1 & 0 & 0 & 0 & 0 & 0 & 0 & 0 & $\mathbf{2}$ \\
Carcharhinus limbatus & 3 & 0 & 0 & 0 & 0 & 0 & 0 & 0 & 0 & 0 & 1 & 0 & $\mathbf{4}$ \\
Carcharhinus sp. & 4 & 4 & 2 & 1 & 2 & 5 & 15 & 8 & 0 & 1 & 2 & 6 & $\mathbf{5 0}$ \\
C. leucas & 1 & 1 & 0 & 0 & 0 & 0 & 1 & 0 & 0 & 0 & 0 & 0 & $\mathbf{3}$ \\
C. falciformis & 0 & 0 & 0 & 0 & 0 & 0 & 22 & 3 & 0 & 7 & 0 & 1 & $\mathbf{3 3}$ \\
C. obscurus & 0 & 0 & 0 & 0 & 0 & 0 & 0 & 0 & 0 & 0 & 0 & 2 & $\mathbf{2}$ \\
C. porosus & 0 & 0 & 0 & 0 & 0 & 0 & 0 & 0 & 0 & 0 & 0 & 5 & $\mathbf{5}$ \\
Carcharias taurus & 0 & 0 & 0 & 0 & 0 & 0 & 3 & 0 & 0 & 1 & 0 & 0 & $\mathbf{4}$ \\
Galeocerdo cuvier & 0 & 0 & 0 & 0 & 0 & 0 & 5 & 0 & 0 & 4 & 0 & 1 & $\mathbf{1 0}$ \\
Isurus oxyrhynchus & 0 & 0 & 0 & 0 & 0 & 0 & 1 & 0 & 0 & 0 & 0 & 0 & $\mathbf{1}$ \\
Rhizoprionodon lalandii & 1 & 13 & 55 & 45 & 93 & 243 & 335 & 50 & 183 & 143 & 7 & 5 & $\mathbf{1 . 1 7 3}$ \\
R. porosus & 0 & 0 & 1 & 3 & 10 & 44 & 16 & 19 & 4 & 70 & 0 & 1 & $\mathbf{1 6 8}$ \\
Rhizoprionodon sp. & 0 & 0 & 0 & 0 & 5 & 4 & 0 & 0 & 0 & 0 & 0 & 0 & $\mathbf{9}$ \\
Squatina guggenheim & 0 & 3 & 10 & 0 & 0 & 0 & 0 & 0 & 0 & 0 & 0 & 1 & $\mathbf{1 4}$ \\
Sphyrna lewini & 0 & 1 & 0 & 0 & 0 & 106 & 33 & 21 & 4 & 3 & 7 & 2 & $\mathbf{1 7 7}$ \\
S. zygaena & 114 & 55 & 38 & 4 & 48 & 205 & 84 & 2 & 0 & 0 & 1 & 302 & $\mathbf{8 5 3}$ \\
\hline \multicolumn{1}{c}{ Total } & $\mathbf{1 2 3}$ & $\mathbf{7 7}$ & $\mathbf{1 0 7}$ & $\mathbf{5 3}$ & $\mathbf{1 5 9}$ & $\mathbf{6 0 7}$ & $\mathbf{5 1 5}$ & $\mathbf{1 0 3}$ & $\mathbf{1 9 1}$ & $\mathbf{2 2 9}$ & $\mathbf{1 8}$ & $\mathbf{3 2 6}$ & $\mathbf{2 . 5 0 8}$
\end{tabular}

Nota: em dezembro e fevereiro foi aplicada metade do esforço de observação.

Tabela III - Número de raias registradas mensalmente nos desembarques da frota em Matinhos-PR de junho de 2009 a maio de 2010

\begin{tabular}{lrrrrrrrrrrrrrr}
\hline & Jun. & Jul. & Ago. & Set. & Out. & Nov. Dez. Jan. & Fev. Mar. Abr. Maio & Total \\
\hline Aetobatus narinari & 0 & 1 & 0 & 0 & 0 & 0 & 0 & 0 & 0 & 0 & 0 & 0 & $\mathbf{1}$ \\
Atlantoraja castelnaui & 0 & 0 & 2 & 0 & 0 & 0 & 0 & 0 & 0 & 0 & 0 & 0 & $\mathbf{2}$ \\
Dasyatis hypostigma & 1 & 0 & 11 & 1 & 2 & 1 & 2 & 1 & 0 & 1 & 0 & 0 & $\mathbf{2 0}$ \\
Dasyatis sp. & 0 & 0 & 0 & 0 & 0 & 0 & 2 & 0 & 0 & 0 & 0 & 1 & $\mathbf{3}$ \\
Gymnura altavela & 5 & 2 & 2 & 1 & 0 & 1 & 0 & 1 & 0 & 2 & 3 & 0 & $\mathbf{1 7}$ \\
Hypanus guttata & 4 & 3 & 2 & 0 & 2 & 4 & 0 & 3 & 2 & 9 & 8 & 5 & $\mathbf{4 2}$ \\
Myliobatis goodei & 0 & 1 & 2 & 0 & 0 & 0 & 11 & 0 & 0 & 0 & 0 & 0 & $\mathbf{1 4}$ \\
Narcine brasiliensis & 6 & 4 & 13 & 2 & 2 & 1 & 0 & 0 & 0 & 0 & 1 & 6 & $\mathbf{3 5}$ \\
Pseudobatos percellens & 29 & 43 & 46 & 11 & 36 & 35 & 31 & 17 & 1 & 22 & 53 & 35 & $\mathbf{3 5 9}$ \\
Pteroplatytrygon violacea & 0 & 0 & 0 & 0 & 0 & 0 & 1 & 0 & 0 & 0 & 0 & 0 & $\mathbf{1}$ \\
Rhinoptera bonasus & 4 & 2 & 12 & 1 & 14 & 7 & 4 & 6 & 0 & 22 & 2 & 0 & $\mathbf{7 4}$ \\
Rhinoptera sp. & 0 & 0 & 0 & 0 & 0 & 0 & 11 & 0 & 0 & 0 & 0 & 0 & $\mathbf{1 1}$ \\
Rioraja agassizii & 0 & 11 & 35 & 1 & 4 & 0 & 3 & 0 & 0 & 0 & 0 & 0 & $\mathbf{5 4}$ \\
Zapteryx brevirostris & 349 & 300 & 435 & 267 & 59 & 130 & 31 & 4 & 5 & 16 & 44 & 159 & $\mathbf{1 . 7 9 9}$ \\
\hline \multicolumn{1}{c}{ Total } & $\mathbf{3 9 8}$ & $\mathbf{3 6 7}$ & $\mathbf{5 6}$ & $\mathbf{2 8 4}$ & $\mathbf{1 1 9}$ & $\mathbf{1 7 9}$ & $\mathbf{9 6}$ & $\mathbf{3 2}$ & $\mathbf{8}$ & $\mathbf{7 2}$ & $\mathbf{1 1 1}$ & $\mathbf{2 0 6}$ & $\mathbf{2 . 4 3 2}$ \\
\hline
\end{tabular}

Nota: em dezembro e fevereiro foi aplicada metade do esforço de observação.

Os desembarques positivos para elasmobrânquios somaram número maior na primavera (outubro a dezembro: 661), coincidindo com o maior número de desembarques totais (661) (Figura 2). Dois meses destacaram-se em desembarques positivos: setembro, iniciando um quadrimestre em que cerca de metade das embarcações capturou elasmobrânquios, e maio, mês isolado com 70\% de ocorrências (Tabela IV). 
Figura 2 - Número de embarcações da frota de Matinhos-PR com desembarque acompanhado de junho de 2009 a maio de 2010, segundo o mês.

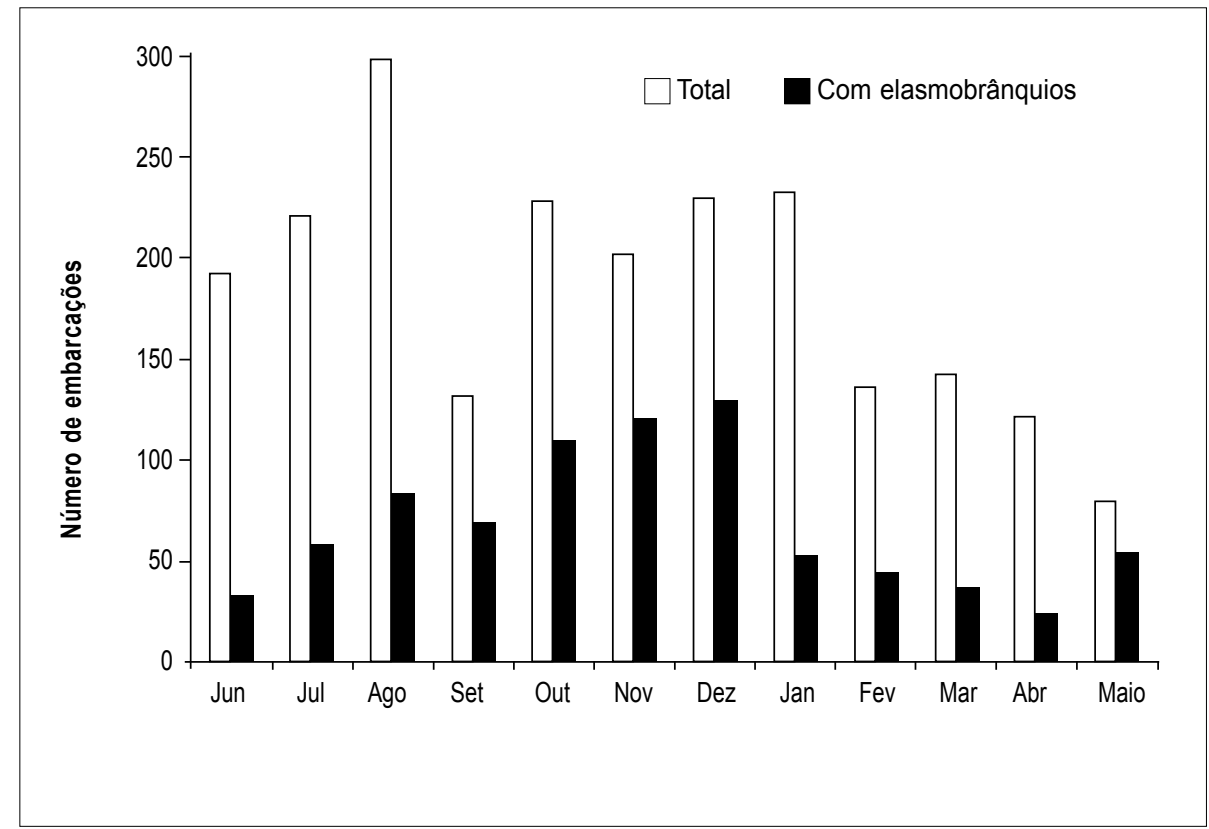

Nota: em dezembro e fevereiro houve metade do esforço de observação.

\begin{tabular}{|c|c|c|c|}
\hline & \multicolumn{2}{|c|}{ Embarcações } & \multirow{2}{*}{$X^{2}$} \\
\hline & Total & $\%$ positivas & \\
\hline Junho 2009 & 193 & 17,1 & - \\
\hline Julho * & 221 & 26,7 & 11,91 \\
\hline Agosto & 300 & 28,0 & 0,19 \\
\hline Setembro * & 132 & 52,3 & 27,77 \\
\hline Outubro & 228 & 48,3 & 0,71 \\
\hline Novembro * & 203 & 59,6 & 5,43 \\
\hline Dezembro & 230 & 56,5 & 0,37 \\
\hline Janeiro * & 234 & 22,7 & 47,50 \\
\hline Fevereiro * & 136 & 32,4 & 5,65 \\
\hline Março & 143 & 25,9 & 1,86 \\
\hline Abril & 121 & 19,8 & 1,71 \\
\hline Maio 2010* & 179 & 70,1 & 103,80 \\
\hline
\end{tabular}

Nota: valores $X^{2}>3,841$ indicam diferença significativa $(0,05)$ de percentagens positivas entre o mês de referência $\left({ }^{*}\right)$ eo anterior, testechi-quadrado dePearson. No destaque, o quadrimestre em que cerca de metade das embarcações continha elasmobrânquios.

Em número, tubarões foram desembarcados majoritariamente de novembro a março e ainda em maio; raias, de junho a setembro e ainda em abril (Figura 3). O número total de elasmobrânquios desembarcados acompanhou o de desembarques positivos para eles, com picos em agosto e novembro (Figura 4). Entretanto, foi em dezembro e fevereiro que o número médio de indivíduos por embarcação positiva alcançou seu máximo, 10. O mínimo ocorreu em outubro, 2,5. 
Figura 3 - Número de raias e tubarões desembarcados pela frota em Matinhos-PR de junho de 2009 a maio de 2010, segundo o mês.

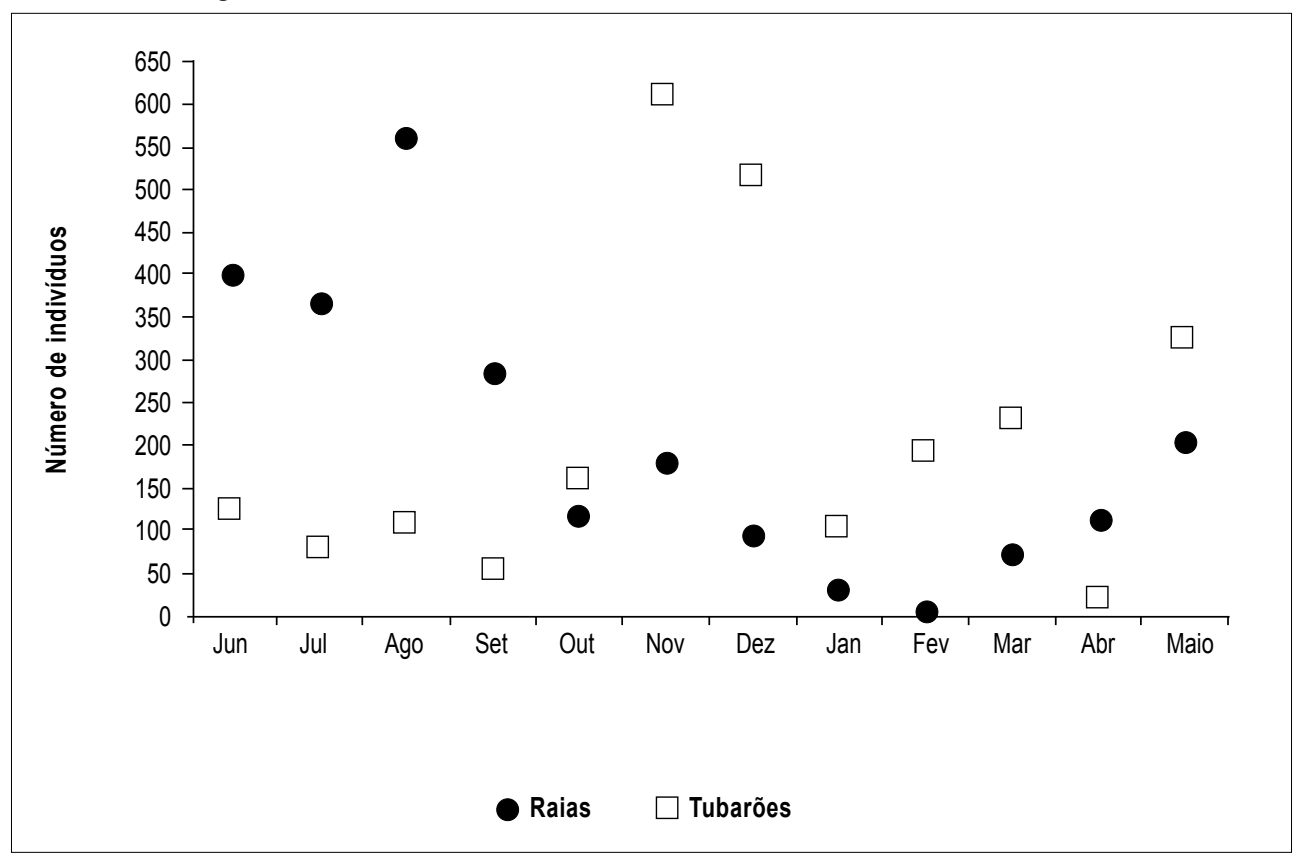

Nota: em dezembro e fevereiro foi aplicada metade do esforço de observação.

Figura 4 - Número de desembarques registrados pela frota em Matinhos-PR de junho de 2009 a maio de 2010, positivos para elasmobrânquios, e número de indivíduos, segundo o mês.

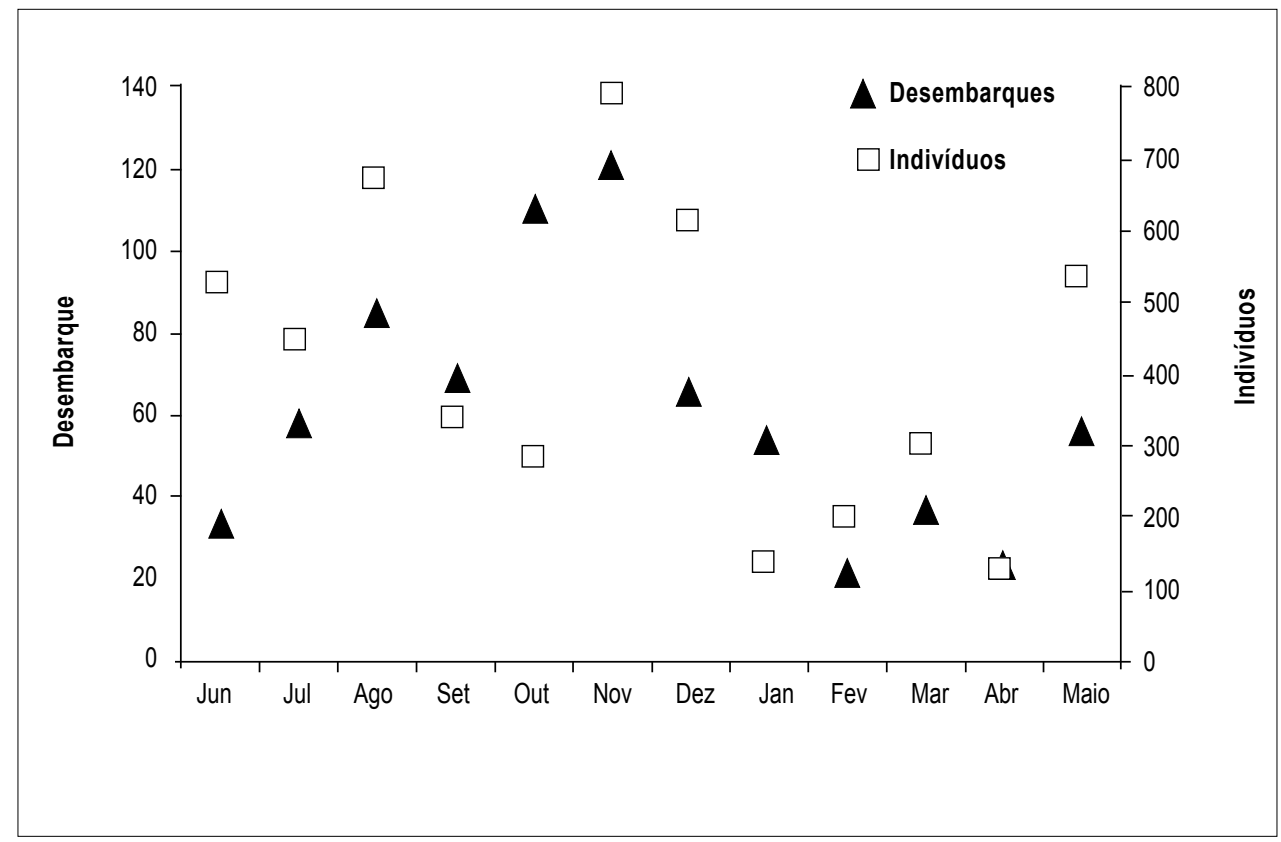

Nota: em dezembro e fevereiro foi aplicada metade do esforço de observação

As redes empregadas eram do tipo simples ou mista. Redes simples eram homogêneas quanto ao tamanho de malha, que variou de 2 a $40 \mathrm{~cm}$. Redes mistas reuniam variadas malhas (Tabelas V e VI). 
Tabela V - Número de tubarões registrados nos desembarques da frota em Matinhos-PR de junho de 2009 a maio de 2010, segundo o tamanho de malha, redes simples e mistas

\begin{tabular}{|c|c|c|c|c|c|c|c|c|c|c|c|c|c|c|c|c|c|}
\hline \multirow{2}{*}{ Malha (cm) } & \multicolumn{16}{|c|}{ Espécies } & \multirow{2}{*}{ Total } \\
\hline & 1 & 2 & 3 & 4 & 5 & 6 & 7 & 8 & 9 & 10 & 11 & 12 & 13 & 14 & 15 & 16 & \\
\hline 4 & 0 & 0 & 0 & 0 & 0 & 0 & 0 & 0 & 0 & 0 & 0 & 0 & 0 & 0 & 0 & 0 & 0 \\
\hline 5 & 0 & 0 & 0 & 0 & 0 & 0 & 0 & 0 & 0 & 0 & 0 & 0 & 0 & 0 & 0 & 0 & 0 \\
\hline 6 & 0 & 2 & 1 & 0 & 0 & 0 & 0 & 0 & 0 & 48 & 8 & 99 & 12 & 0 & 0 & 0 & 170 \\
\hline 7 & 0 & 1 & 0 & 0 & 0 & 0 & 0 & 0 & 0 & 14 & 9 & 53 & 7 & 4 & 0 & 0 & 88 \\
\hline 8 & 0 & 0 & 0 & 0 & 0 & 0 & 0 & 0 & 0 & 0 & 0 & 1 & 0 & 0 & 0 & 0 & 1 \\
\hline 9 & 0 & 12 & 1 & 13 & 0 & 3 & 0 & 3 & 1 & 157 & 25 & 538 & 93 & 0 & 1 & 0 & 847 \\
\hline 10 & 0 & 7 & 0 & 3 & 0 & 0 & 2 & 0 & 0 & 220 & 34 & 157 & 16 & 4 & 0 & 2 & 445 \\
\hline 11 & 1 & 0 & 0 & 0 & 0 & 0 & 0 & 0 & 0 & 30 & 0 & 3 & 0 & 0 & 0 & 0 & 34 \\
\hline 12 & 0 & 1 & 0 & 0 & 0 & 0 & 0 & 0 & 0 & 3 & 1 & 2 & 0 & 0 & 0 & 0 & 7 \\
\hline 14 & 0 & 0 & 0 & 0 & 0 & 0 & 0 & 0 & 0 & 1 & 0 & 1 & 0 & 0 & 0 & 0 & 2 \\
\hline 16 & 0 & 0 & 0 & 0 & 0 & 0 & 0 & 0 & 0 & 22 & 9 & 1 & 1 & 0 & 4 & 0 & 37 \\
\hline 18 & 3 & 12 & 1 & 2 & 1 & 1 & 0 & 0 & 0 & 65 & 9 & 10 & 1 & 0 & 6 & 0 & 111 \\
\hline 20 & 0 & 1 & 0 & 0 & 0 & 0 & 0 & 0 & 0 & 2 & 0 & 0 & 1 & 0 & 0 & 0 & 4 \\
\hline 30 & 0 & 1 & 0 & 0 & 0 & 0 & 0 & 0 & 0 & 6 & 0 & 0 & 0 & 0 & 0 & 0 & 7 \\
\hline 40 & 0 & 1 & 0 & 0 & 0 & 0 & 0 & 0 & 0 & 3 & 1 & 0 & 0 & 0 & 0 & 0 & 5 \\
\hline 2 ou 3 & 6 & 0 & 0 & 0 & 0 & 0 & 0 & 0 & 0 & 0 & 1 & 0 & 0 & 0 & 0 & 0 & 7 \\
\hline $6+7$ & 0 & 0 & 0 & 0 & 0 & 0 & 0 & 0 & 0 & 0 & 0 & 2 & 0 & 0 & 0 & 0 & 2 \\
\hline $6+18$ & 0 & 0 & 0 & 0 & 0 & 0 & 0 & 0 & 0 & 0 & 0 & 1 & 0 & 0 & 0 & 0 & 1 \\
\hline $7+8$ & 0 & 0 & 0 & 0 & 0 & 0 & 0 & 0 & 0 & 0 & 1 & 2 & 0 & 0 & 0 & 0 & 3 \\
\hline $7+9$ & 0 & 0 & 0 & 0 & 0 & 0 & 0 & 0 & 0 & 0 & 0 & 3 & 0 & 0 & 0 & 0 & 3 \\
\hline $7+18$ & 0 & 0 & 0 & 0 & 0 & 0 & 0 & 0 & 0 & 0 & 1 & 3 & 0 & 0 & 0 & 0 & 4 \\
\hline $9+10$ & 0 & 7 & 0 & 1 & 0 & 0 & 0 & 1 & 0 & 139 & 43 & 141 & 19 & 0 & 0 & 0 & 351 \\
\hline $9+12$ & 0 & 0 & 0 & 1 & 0 & 1 & 0 & 3 & 0 & 21 & 1 & 22 & 2 & 0 & 0 & 0 & 51 \\
\hline $9+18$ & 0 & 0 & 0 & 0 & 1 & 0 & 0 & 0 & 0 & 9 & 0 & 0 & 0 & 0 & 0 & 0 & 10 \\
\hline $10+11$ & 0 & 0 & 0 & 0 & 0 & 0 & 0 & 0 & 0 & 2 & 1 & 3 & 0 & 0 & 0 & 0 & 6 \\
\hline $10+12$ & 0 & 0 & 0 & 0 & 0 & 0 & 0 & 0 & 0 & 2 & 20 & 10 & 6 & 0 & 0 & 0 & 38 \\
\hline $10+16$ & 0 & 0 & 0 & 1 & 0 & 0 & 0 & 0 & 0 & 0 & 1 & 39 & 0 & 0 & 0 & 0 & 41 \\
\hline $12+18$ & 0 & 0 & 0 & 0 & 0 & 0 & 0 & 0 & 0 & 13 & 0 & 0 & 0 & 0 & 0 & 0 & 13 \\
\hline $16+18$ & 0 & 0 & 0 & 0 & 0 & 0 & 1 & 0 & 0 & 0 & 0 & 0 & 0 & 0 & 0 & 0 & 1 \\
\hline $18+20$ & 0 & 0 & 0 & 0 & 0 & 0 & 0 & 0 & 0 & 1 & 0 & 0 & 0 & 0 & 3 & 0 & 4 \\
\hline $6+7+8$ & 0 & 0 & 0 & 0 & 0 & 0 & 0 & 0 & 0 & 0 & 1 & 0 & 0 & 0 & 0 & 0 & 1 \\
\hline $7+8+9$ & 0 & 0 & 0 & 0 & 0 & 0 & 0 & 0 & 0 & 1 & 5 & 28 & 4 & 1 & 0 & 0 & 39 \\
\hline $7+9+18$ & 0 & 0 & 0 & 0 & 0 & 0 & 0 & 0 & 0 & 1 & 0 & 0 & 0 & 0 & 0 & 0 & 1 \\
\hline $9+10+11$ & 0 & 0 & 0 & 0 & 0 & 0 & 0 & 0 & 0 & 1 & 0 & 3 & 0 & 0 & 0 & 0 & 4 \\
\hline $9+10+16$ & 0 & 0 & 0 & 0 & 0 & 0 & 0 & 0 & 0 & 0 & 0 & 5 & 1 & 0 & 0 & 0 & 6 \\
\hline $9+10+20$ & 0 & 0 & 0 & 1 & 0 & 0 & 0 & 0 & 0 & 30 & 0 & 1 & 0 & 0 & 0 & 0 & 32 \\
\hline Sem Info & 0 & 5 & 0 & 11 & 0 & 0 & 1 & 3 & 0 & 62 & 6 & 45 & 5 & 0 & 0 & 0 & 138 \\
\hline Total & 10 & 50 & 3 & 33 & 2 & 5 & 4 & 10 & 1 & 853 & 177 & 1173 & 168 & 9 & 14 & 2 & 2.514 \\
\hline
\end{tabular}

Legenda: 1) Carcharhinus limbatus; 2) Carcharhinus sp.; 3) Carcharhinus leucas; 4) Carcharhinus falciformis; 5) C. obscurus; 6) C. porosus; 7) Carcharias taurus; 8) Galeocerdo cuvier; 9) Isurus oxyrhynchus; 10) Sphyrna zygaena; 11) S. lewini; 12) Rhizoprionodon lalandii; 13) R. porosus; 14) Rhizoprionodon sp.; 15) Squatina guggenheim; 16) Alopias vulpinus. 
Tabela VI - Número de raias registradas nos desembarques da frota em Matinhos-PR de junho de 2009 a maio de 2010, segundo o tamanho de malha, redes simples e mistas

\begin{tabular}{|c|c|c|c|c|c|c|c|c|c|c|c|c|c|c|c|}
\hline \multirow{2}{*}{$\begin{array}{c}\text { Malha } \\
\text { (cm) }\end{array}$} & \multicolumn{14}{|c|}{ Espécies } & \multirow{2}{*}{ Total } \\
\hline & 1 & 2 & 3 & 4 & 5 & 6 & 7 & 8 & 9 & 10 & 11 & 12 & 13 & 14 & \\
\hline 4 & 0 & 0 & 0 & 0 & 1 & 0 & 0 & 0 & 0 & 0 & 0 & 0 & 0 & 0 & 1 \\
\hline 5 & 0 & 0 & 0 & 0 & 0 & 0 & 0 & 0 & 0 & 1 & 0 & 0 & 0 & 0 & 1 \\
\hline 6 & 1 & 0 & 0 & 0 & 0 & 0 & 1 & 0 & 0 & 3 & 0 & 0 & 0 & 0 & 5 \\
\hline 7 & 0 & 0 & 0 & 0 & 0 & 0 & 2 & 0 & 0 & 0 & 0 & 0 & 0 & 0 & 2 \\
\hline 8 & 0 & 0 & 0 & 0 & 0 & 0 & 8 & 0 & 0 & 0 & 0 & 0 & 0 & 0 & 8 \\
\hline 9 & 1 & 0 & 0 & 0 & 0 & 0 & 3 & 0 & 0 & 3 & 1 & 0 & 0 & 0 & 8 \\
\hline 10 & 1 & 2 & 1 & 0 & 0 & 1 & 0 & 13 & 0 & 4 & 3 & 0 & 10 & 0 & 35 \\
\hline 11 & 0 & 0 & 0 & 0 & 0 & 0 & 0 & 1 & 0 & 0 & 0 & 0 & 0 & 0 & 1 \\
\hline 12 & 0 & 0 & 0 & 0 & 0 & 0 & 0 & 0 & 0 & 2 & 0 & 0 & 0 & 0 & 2 \\
\hline 14 & 0 & 0 & 0 & 0 & 0 & 0 & 0 & 0 & 0 & 0 & 0 & 0 & 0 & 0 & 0 \\
\hline 16 & 2 & 5 & 0 & 0 & 1 & 7 & 97 & 6 & 0 & 519 & 23 & 0 & 1 & 2 & 663 \\
\hline 18 & 21 & 9 & 0 & 1 & 8 & 10 & 190 & 40 & 0 & 751 & 19 & 1 & 1 & 0 & 1.051 \\
\hline 20 & 2 & 1 & 0 & 0 & 0 & 1 & 5 & 0 & 0 & 6 & 0 & 0 & 1 & 0 & 16 \\
\hline 40 & 0 & 1 & 0 & 0 & 0 & 0 & 1 & 2 & 0 & 0 & 0 & 0 & 0 & 0 & 4 \\
\hline 2 ou 3 & 6 & 1 & 0 & 0 & 4 & 15 & 5 & 2 & 0 & 129 & 0 & 0 & 0 & 0 & 162 \\
\hline $6+7$ & 0 & 0 & 0 & 0 & 0 & 0 & 0 & 0 & 0 & 1 & 0 & 0 & 0 & 0 & 1 \\
\hline $6+18$ & 0 & 0 & 0 & 0 & 0 & 0 & 0 & 0 & 0 & 1 & 0 & 0 & 0 & 0 & 1 \\
\hline $7+8$ & 0 & 0 & 0 & 0 & 0 & 0 & 0 & 0 & 0 & 0 & 0 & 0 & 0 & 0 & 0 \\
\hline $7+9$ & 0 & 0 & 0 & 0 & 0 & 0 & 0 & 0 & 0 & 0 & 0 & 0 & 0 & 0 & 0 \\
\hline $7+18$ & 0 & 0 & 0 & 0 & 0 & 0 & 1 & 0 & 0 & 4 & 0 & 0 & 0 & 0 & 5 \\
\hline $9+10$ & 0 & 0 & 0 & 0 & 0 & 0 & 0 & 1 & 0 & 0 & 0 & 0 & 0 & 0 & 1 \\
\hline $9+12$ & 0 & 0 & 0 & 0 & 0 & 0 & 0 & 0 & 0 & 0 & 0 & 0 & 0 & 0 & 0 \\
\hline $9+18$ & 0 & 0 & 0 & 0 & 0 & 0 & 0 & 0 & 0 & 9 & 0 & 0 & 0 & 0 & 9 \\
\hline $10+11$ & 0 & 0 & 0 & 0 & 0 & 0 & 0 & 3 & 0 & 0 & 0 & 0 & 0 & 0 & 3 \\
\hline $10+12$ & 1 & 0 & 0 & 0 & 0 & 0 & 1 & 1 & 0 & 0 & 0 & 0 & 0 & 0 & 3 \\
\hline $10+16$ & 0 & 0 & 0 & 0 & 0 & 0 & 0 & 0 & 0 & 0 & 0 & 0 & 0 & 0 & 0 \\
\hline $12+18$ & 0 & 0 & 0 & 0 & 0 & 0 & 0 & 0 & 0 & 0 & 0 & 0 & 0 & 0 & 0 \\
\hline $16+18$ & 4 & 1 & 0 & 0 & 3 & 0 & 11 & 0 & 0 & 141 & 0 & 0 & 0 & 0 & 160 \\
\hline $18+20$ & 2 & 0 & 0 & 0 & 0 & 0 & 16 & 2 & 0 & 97 & 5 & 0 & 0 & 0 & 122 \\
\hline $6+7+8$ & 0 & 0 & 0 & 0 & 0 & 0 & 0 & 0 & 0 & 0 & 0 & 0 & 0 & 0 & 0 \\
\hline $7+8+9$ & 0 & 0 & 0 & 0 & 0 & 0 & 0 & 1 & 0 & 0 & 0 & 0 & 0 & 0 & 1 \\
\hline $7+9+18$ & 1 & 0 & 0 & 0 & 0 & 0 & 0 & 0 & 0 & 0 & 0 & 0 & 0 & 0 & 1 \\
\hline $9+10+11$ & 0 & 0 & 0 & 0 & 0 & 0 & 0 & 0 & 0 & 0 & 0 & 0 & 0 & 0 & 0 \\
\hline $9+10+16$ & 0 & 0 & 0 & 0 & 0 & 0 & 1 & 0 & 0 & 0 & 0 & 0 & 1 & 0 & 2 \\
\hline Sem Info & 0 & 0 & 0 & 2 & 1 & 1 & 17 & 2 & 11 & 128 & 3 & 0 & 0 & 0 & 165 \\
\hline TOTAL & 42 & 20 & 1 & 3 & 18 & 35 & 359 & 74 & 11 & 1.799 & 54 & 1 & 14 & 2 & 2.433 \\
\hline
\end{tabular}

Legenda: 1) Hypanus guttatus; 2) Dasyatis hypostigma;3) Pteroplatytrygon violacea; 4) Dasyatis sp.; 5) Gymnura altavela; 6) Narcine brasiliensis; 7) Pseudobatos percellens; 8) Rhinoptera bonasus; 9) Rhinoptera sp.; 10) Zapteryx brevirostris; 11) Rioraja agazissii; 12) Aetobatus narinari; 13) Myliobatis goodei; 14) Atlantoraja castelnaui.

Redes tipo simples, com maior captura de tubarões, foram as de malhas 6, 7, 9, 10 e $18 \mathrm{~cm}$ (Figura 5). As duas espécies mais desembarcadas de tubarões tiveram ápices de ocorrências nas malhas 9 e $18 \mathrm{~cm}$ (R. lalandii) e $10 \mathrm{~cm}$ (S. zygaena) (Figura 6). Grande número de indivíduos de $S$. zygaena, $S$. lewini e $R$. lalandii esteve associado também a redes com malhas 9+10 cm do tipo mista (Tabela IV). A ocorrência de Sphyrna associou-se aos alvos cavala, pescada e tainha e incluiu neonatos.

Redes tipo simples com maior captura de raias foram as de malhas 10, 16, 18 e $20 \mathrm{~cm}$ (Figura 5). As duas espécies mais desembarcadas de raias, Z. brevirostris e R. percellens, tiveram ápices de ocorrências na malha $18 \mathrm{~cm}$ (Figura 7). Grande número de indivíduos da primeira esteve associado também às malhas 2 ou $3 \mathrm{~cm}$ e em redes mistas, $16+18 \mathrm{~cm}$ (Tabela V). Grande parte de Pseudobatos esteve associada a redes para linguado, alvo no inverno. 
Figura 5 - Número de espécies de tubarões e raias desembarcados pela frota em Matinhos-PR de junho de 2009 a maio de 2010, segundo o tamanho da malha redes simples
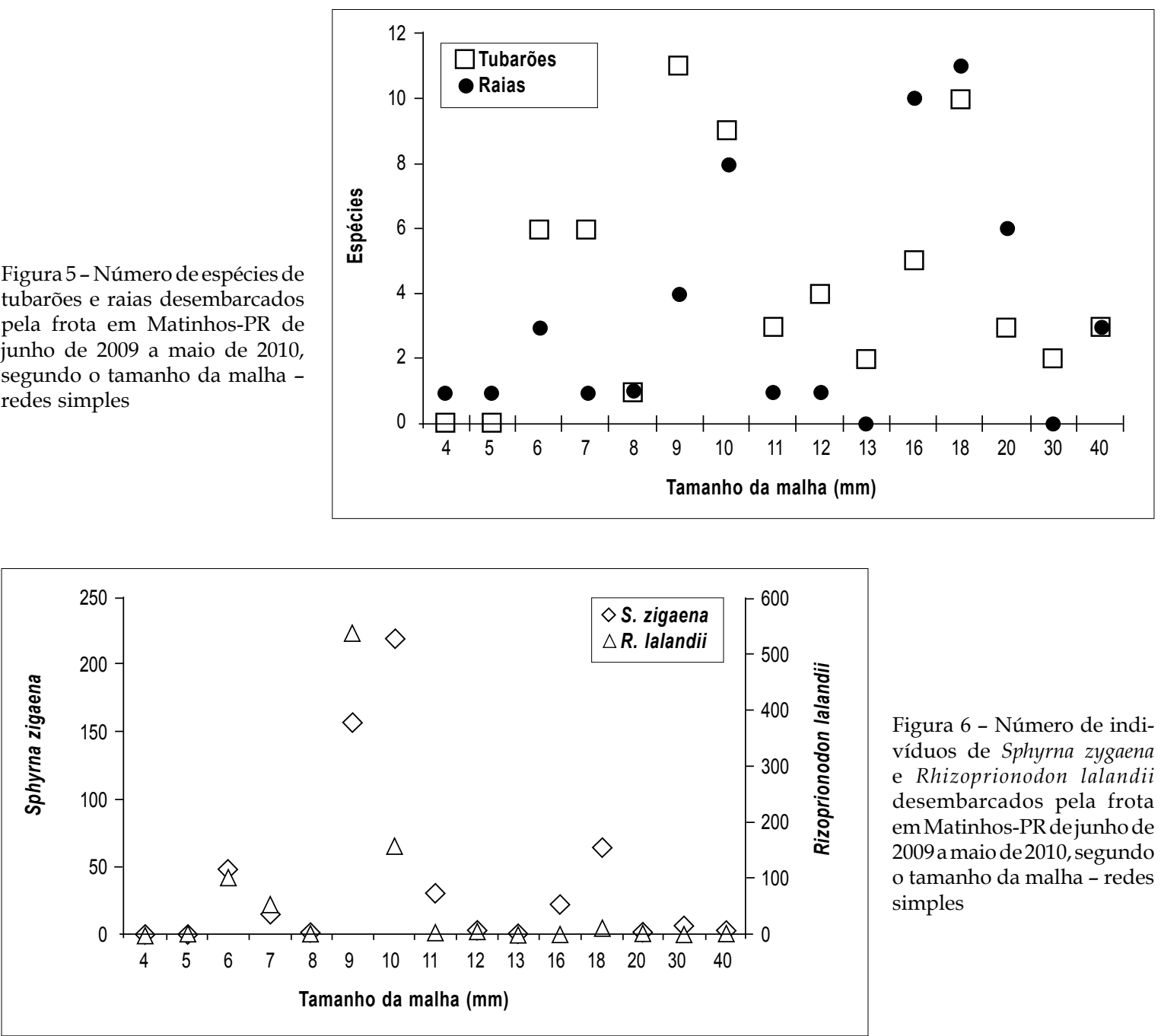

Figura 6 - Número de indivíduos de Sphyrna zygaena e Rhizoprionodon lalandii em Matinhos-PR dejunho de 2009 a maio de 2010 , segundo o tamanho da malha - redes simples desembarcados pela frota
Figura 7 - Número de indivíduos de Zapteryx brevirostris e Pseudobatos percellens desembarcados pela frota em Matinhos-PR de junho de 2009 a maio de 2010, segundo o tamanho da malha - redes simples



Cerca de $16 \%$ dos indivíduos foram desembarcados eviscerados, 797 dos 4.842 acessados para tal verificação. Das espécies de tubarões, metade foi sempre desembarcada inteira; das espécies de raias, menos da metade. Indivíduos de três gêneros - Rhizoprionodon, 
Dasyatis e Rhinoptera, espécies não identificadas - tiveram a maioria dos indivíduos desembarcados eviscerados (Figura 8).

Figura 8 - Frequência relativa de tubarões (T) e raias (R) desembarcados inteiros pela frota em Matinhos-PR de junho de 2009 a maio de 2010, segundo a espécie

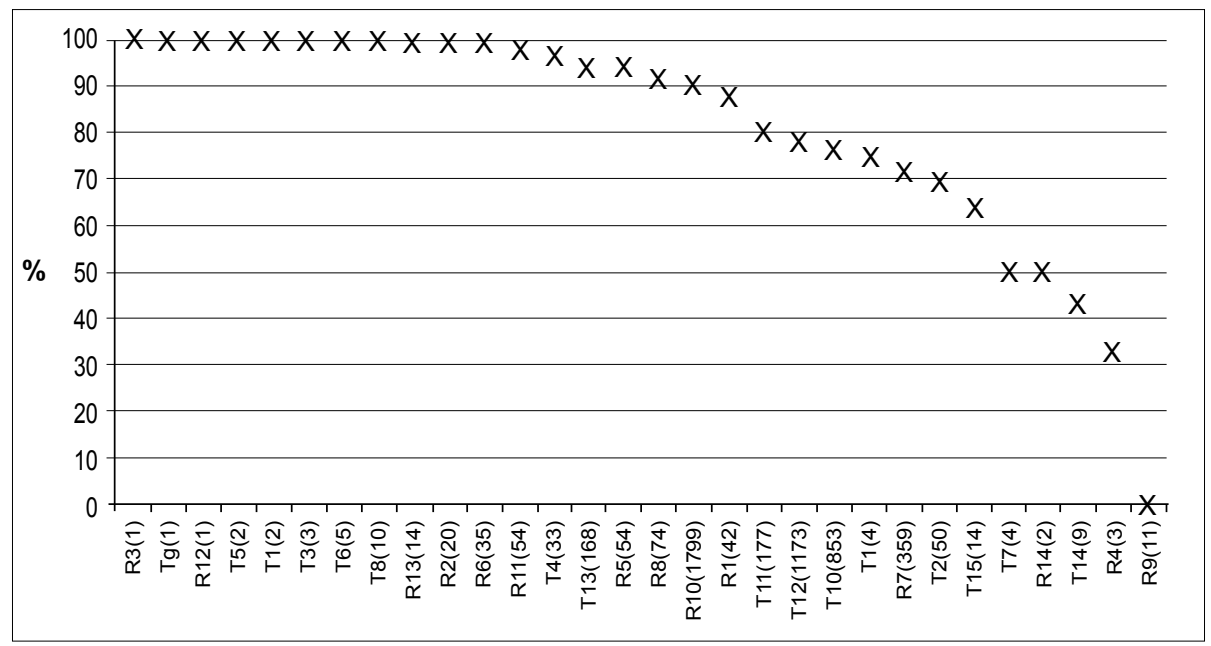

A biomassa desembarcada, apenas considerados os indivíduos inteiros, foi de 6,03 $t$, sendo 3,68 $\mathrm{t}$ de tubarões e 2,35 $\mathrm{t}$ de raias. O peso médio dos tubarões foi de 1,466 kg (DP = $3,83)$ e o das raias de $0,971 \mathrm{~kg}(\mathrm{DP}=2,80)$. As estações com maior biomassa de desembarque de tubarões foram primavera e outono, superando 1,0 $\mathrm{t}$; com maior desembarque de raias no inverno, mais de 0,9 $\mathrm{t}$ (Figura 9). No período total, e considerados apenas os indivíduos desembarcados inteiros, os tubarões com maior biomassa foram S. zygaena $(2.014 \mathrm{~kg})$ e $R$. lalandii (792 kg); as raias, Z. brevirostris (934 kg) e P. percellens (532 kg) (Figura 10).

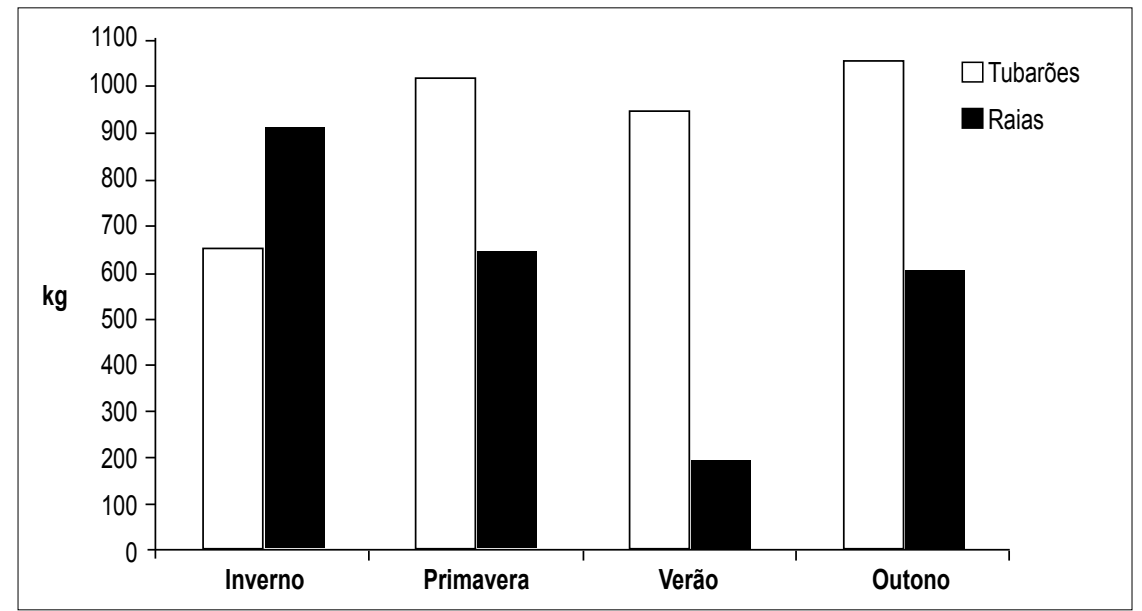

Figura 9 - Distribuição dos valores de produção em kg de tubarões e raias desembarcados pela frota em Matinhos-PR de junho de 2009 a maio de 2010. Nota: primavera e verão: esforço de coleta $1 / 6$ menor que nas demais estações.

Quanto ao estágio de desenvolvimento, os exemplares de tubarões ocorreram em maior frequência como neonatos, ou imaturos (Figura 11); os de raias, ou imaturos, ou maduros (Figura 12). O maior volume desembarcado de neonatos, em número absoluto, foi registrado para R. lalandii (277 indivíduos), S. lewini (106), R. porosus (80) e C. falciformis (27). A maior abundância de exemplares maduros, em número absoluto, foi registrada em R. lalandii (401 indivíduos) e P. percellens (242). 
Figura 10 - Distribuição dos valores de peso total (escala logarítmica) de tubarões e raias desembarcados inteiros pela frota em Matinhos-PR de junho de 2009 a maio de 2010, segundo a espécie.

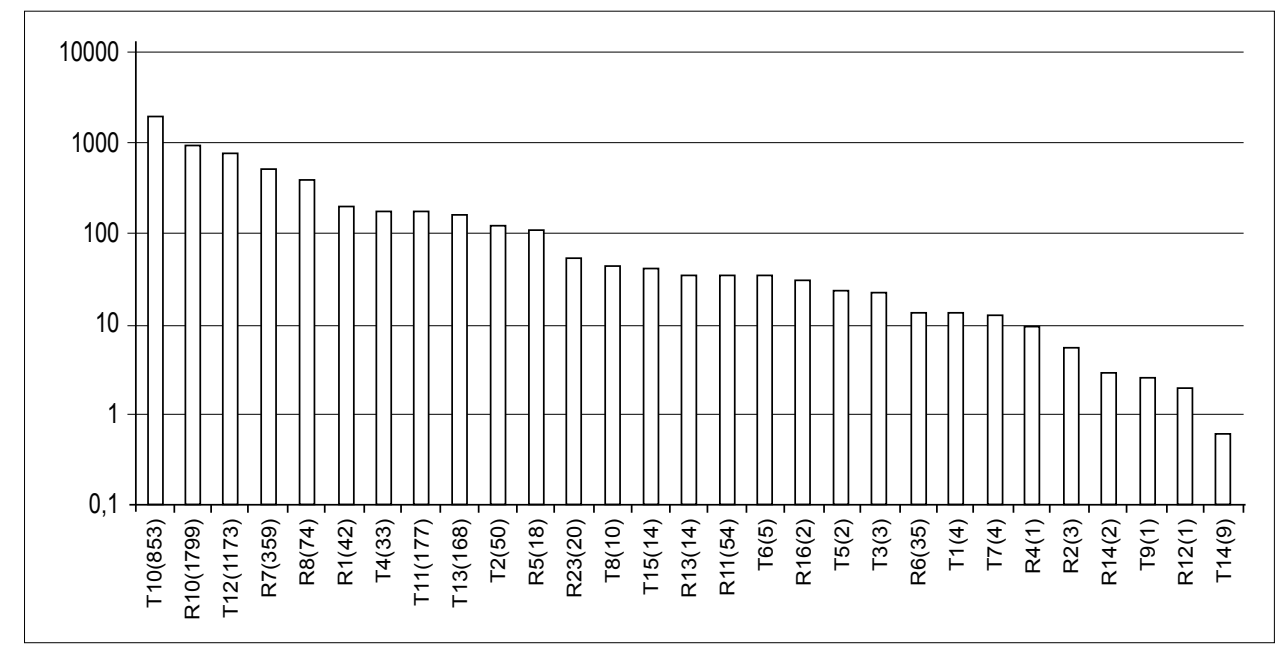

Nota: ( ): número de indivíduos pesados, código das espécies: Tabelas 5 (T) e 6 (R).

Figura 11 - Distribuição das frequências relativas de tubarões desembarcados pela frota em Matinhos-PR de junho de 2009 a maio de 2010, segundo o sexo (M: machos; F: fêmeas) e estágio de desenvolvimento.

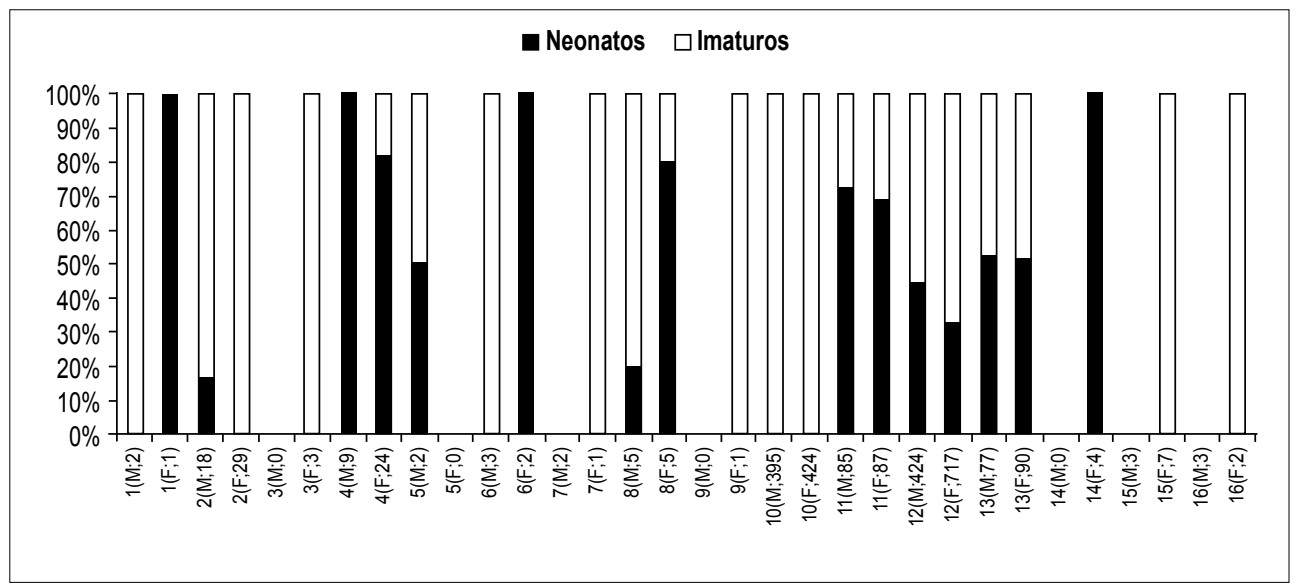

Nota: código das espécies conforme Tabelas 5 (T) e 6 (R), ( ): número de indivíduos.

Figura 12 - Distribuição das frequências relativas de raias desembarcadas pela frota em Matinhos-PR de junho de 2009 a maio de 2010, segundo o sexo (M: machos; F: fêmeas) e estágio de desenvolvimento.

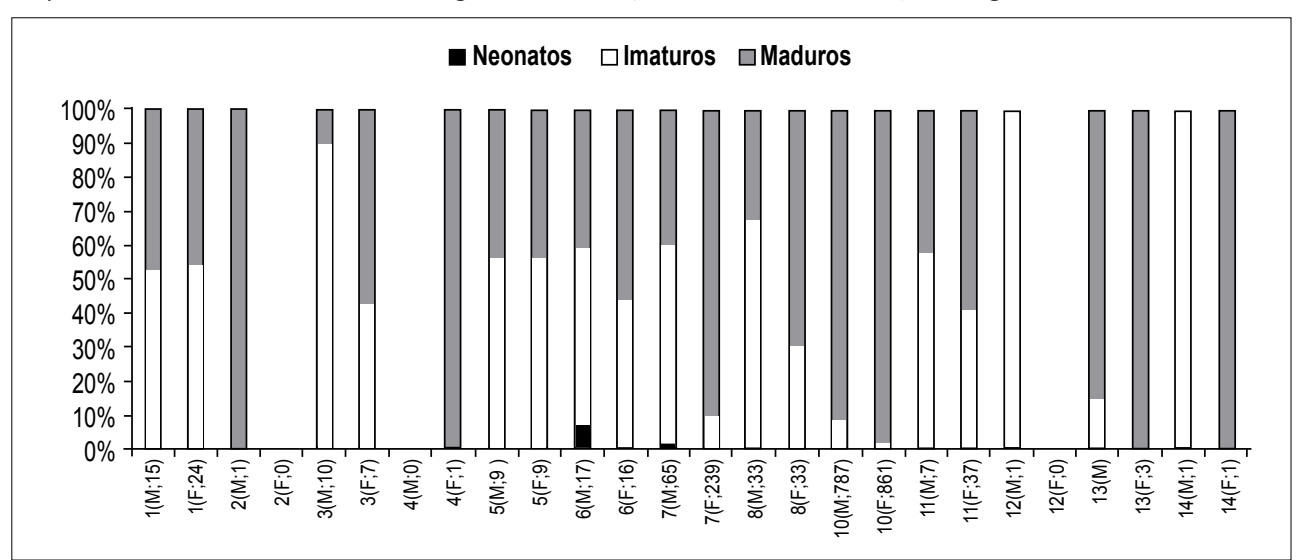

Nota: código das espécies conforme Tabelas 5 (T) e 6 (R), ( ): número de indivíduos. 


\section{DISCUSSÃO}

As 26 espécies registradas nos desembarques têm ocorrência conhecida na costa SulSudeste e correspondem a quase um terço de todas as espécies do grupo (83), cuja ocorrência na costa paranaense foi compilada por Bornatowski et al. (2009). Notadamente, os tubarões e as raias mais frequentes - R. lalandii, S. zygaena, Z. brevirostris e P. percellens - são rotineiramente detectados nos desembarques de redes de emalhe e de arrasto camaroeiro no litoral sul do Paraná e norte de Santa Catarina (Bornatowski \& Abilhoa, 2012). Esses autores registraram na pesca artesanal 16 espécies de tubarões e 15 de raias. Quanto aos tubarões, não citam Carcharhinus leucas e C. porosus e acrescentam Squalus sp., Squatina occulta, Mustelus canis e C. brevipinna, que pode corresponder a Carcharhinus sp. Para as raias, não citam Pteroplatytrygon violacea e Atlantoraja narinari e acrescentam Rhinobatos (Pseudobatos) horkelli, Atlantoraja cyclophora, Mobula hypostoma e Rhinoptera brasiliensis, que pode corresponder a Rhinoptera sp. Nos desembarques da região, apenas sete espécies de tubarões e 11 de raias foram observadas por Costa e Chaves (2006), diferença em relação ao presente trabalho que pode ser atribuída ao fato de os autores, com tempo menor de observações, terem acessado 15 vezes menos indivíduos. Na costa brasileira como um todo, Dias Neto (2011) reúne literatura e reporta mais de 80 espécies de tubarões e 40 de raias. Como esperado, há diferenças entre regiões quanto à composição específica e dominância: em águas rasas do Maranhão, por exemplo, Dasyatis guttata (Hypanus guttatus) foi a raia mais abundante, e Rhinobatos (Pseudobatos) percellens, uma das menos comuns, no levantamento de Nunes et al. (2005).

A frota de pequena escala, diferente da industrial, efetua desembarques quase diários e dispõe de menor infraestrutura para corte dos pescados a bordo. Assim, comumente os peixes são desembarcados inteiros, o que, no caso de elasmobrânquios, é importante para fins de fiscalização (distinção entre espécies, medição de exemplares, combate ao finning) e de obtenção de dados biológicos (trato genital). No presente trabalho, o desembarque de indivíduos inteiros superou $80 \%$ dos casos, o que favoreceu a identificação específica e a tomada de informações biométricas e reprodutivas.

Constatou-se que o desembarque de tubarões foi, em número, maior em meses de primavera e verão, enquanto em biomassa, na primavera e outono. $\mathrm{O}$ fato indica ocorrência de indivíduos de pequeno porte nos meses mais quentes, muitos dos quais neonatos. Quanto às raias, o desembarque cresce no inverno, tanto em número como em biomassa. Tais picos não necessariamente refletem maior abundância de tubarões ou raias na região, pois a abundância de desembarque é influenciada por fatores como área de pesca, petrechos de captura, defeso de recursos-alvo do período, valor de comercialização (Robert \& Chaves, 2006). Ao ajustar-se, mediante duplicação, o número de observações de desembarque em dezembro e fevereiro, constata-se que setembro marca o início de quadrimestre com ocorrências significativamente maiores, com elasmobrânquios presentes em cerca de $50 \%$ dos desembarques. Outro pico é observado em maio, $70 \%$. Inverno e primavera foram destacados por Costa e Chaves (2006) como épocas de maior desembarque de elasmobrânquios na região, situação que aparentemente persiste, ao menos quanto à primavera. $\mathrm{O}$ menor esforço de observação na primavera e verão influenciou parte dos resultados, não quanto à composição em espécies, tampouco quanto à dominância particular de quatro delas, mas quanto ao número de indivíduos desembarcados. Caso o esforço amostral tivesse sido o mesmo em dezembro e fevereiro, possivelmente 
dezembro - em vez de novembro - teria sido o mês com maior desembarque total de elasmobrânquios. Isso decorreria do desembarque dos tubarões $R$. lalandii e S. zygaena, expressivo em meses de verão.

As diferenças registradas entre redes simples e mistas, expressas por capturas maiores nas simples, bem como entre tamanhos de malhas, com tubarões majoritariamente capturados em malha $9 \mathrm{~cm}$ e raias em malha $18 \mathrm{~cm}$, podem dever-se a esforços diferenciados entre categorias. A mudança de malhas é comum na região, dependendo do alvo e da época (Robert \& Chaves, 2006), o que dispersa o grau de pressão sobre espécies e sobre classes de tamanho e de maturidade sexual. Parte das ocorrências deu-se na condição de fauna acompanhante de outros recursos-alvo, como Narcine no arrasto de camarão e Pseudobatos nas redes para linguado.

As raias foram abundantes em estágio maduro, assim como a captura de neonatos de tubarões. Portanto, alerta-se para o impacto que a pesca na região exerce sobre a reprodução de elasmobrânquios. Em 154 dias registrou-se desembarque de 4.941 exemplares; portanto, no total de um ano cerca de 10 mil exemplares foram desembarcados. O desembarque observado de 6 toneladas em 154 dias de coleta, considerando apenas os indivíduos inteiros, gera expectativa de que, em 12 meses, a captura de elasmobrânquios pela frota de Matinhos tenha superado 13 toneladas. Diante do desembarque nacional de condrícties, estimado em 11.000 toneladas/ano (Dias Neto, 2011), o valor absoluto é baixo, consequência de ser frota de pequena escala e em apenas uma localidade da costa brasileira. Fato agravante é que parte da biomassa envolve neonatos, mais expressivos em número que em peso. Trabalhos prévios relatam que a região é área de parto para G. cuvier, R. lalandii, $R$. porosus, S. lewini, N. brasiliensis e R. agassizii (Costa \& Chaves, 2006), e neste trabalho neonatos foram registrados nas primeiras quatro espécies. O grupo é sensível, com crescimento lento, maturação sexual tardia, baixa fecundidade e alta longevidade. Ao menos nove das 26 espécies encontram-se nas categorias Criticamente em perigo e Em perigo de extinção, e algumas das demais podem não ter sido categorizadas por falta de informações suficientes para tal.

A partir dos resultados aqui obtidos, recomenda-se, para conservação da condrofauna de ocorrência no litoral do estado do Paraná: 1) ações educativas com os pescadores em favor do descarte de animais vivos - neonatos, Narcine no arrasto camaroeiro, e jovens e adultos de espécies com captura proibida; 2) priorização da proteção de Carcharias taurus, Pseudobatos percellens, acompanhante da pesca de linguado, e Squatina sp., alvo da rede malhão ( $\geq 30 \mathrm{~cm}$ ). O artigo $3^{\circ}$ da Portaria MMA 445/2014 estipula que, para as espécies da categoria Vulnerável, ao menos duas das espécies aqui registradas, poderá ser permitido o uso sustentável, ainda aguardando regulamentação e autorização pelos órgãos federais competentes. Na região de atuação da frota estudada, faz-se necessário conhecer a situação dos estoques, em densidade e parâmetros biológicos. O presente trabalho retrata a situação nos anos 2009 e 2010, por isso um novo estudo será importante para a realização de análises comparativas.

Agradecimentos - os autores agradecem aos pescadores de Matinhos, pelo indispensável e cordial auxílio prestado na obtenção de material e disponibilização de informações, e aos consultores da revista Arquivos de Ciências do Mar, pelo zelo dedicado à avaliação do manuscrito. Trabalho realizado com bolsas pós-doutorado do CNPq a Maurício Pinto de Almeida (processo 150799/2009-8) e de Iniciação Científica da UFPR a Matheus Platner. 


\section{REFERÊNCIAS BIBLIOGRÁFICAS}

Aguiar, A.A. Proposta de uma nova chave de identificação para os Myliobatiformes sensu Compagno, 1999 (Chondrichthyes: Elasmobranchii: Myliobatiformes) do Brasil. Monografia de bacharelado, graduação em Ciências Biológicas, Universidade Federal do Rio de Janeiro, 56 p., Rio de Janeiro, 1999.

Barausse, V.; Curkovic A.; Finotto L.; Riginellan E.; Visentin, E. \& Mazzoldi, C. The role of fisheries and the environment in driving the decline of elasmobranchs in the northern Adriatic Sea. ICES J. Mar. Sci., v. 71, n. 7, p. 1593-1603, 2014.

Baum J.K. \& Myers, R.A. Shifting baselines and the decline of pelagic sharks in the Gulf of Mexico. Department of Biology, Dalhousie University, Ecology Letters 7, p. 135-145, 2004.

Bornatowski, H. \& Abilhoa, V. Tubarões e raias capturados pela pesca artesanal no Paraná: Guia de Identificação. Hori Cadernos Técnicos, 124 p., Curitiba, 2012.

Bornatowski, H.; Abilhoa, V. \& Charvet-Almeida, P. Elasmobranchs of the Paraná Coast, southern Brazil, south-western Atlantic. Mar. Biodivers. Rec., v. 2, doi.org/10.1017/ S1755267209990868, 2009.

Camhi, M.; Fowler, S.; Musick, J.; Bräutigam \& Fordjam, S. Sharks and Their relatives: ecology and conservation. Occasional Paper of the IUCN Species Survival Commission, n. 20, Oxford, p. 1-39, 1998.

Casey, J.M. \& Myers, R.A. Near extinction of a large, widely distributed fish. Science, v. 281, p. 690-69, 1998.

Castro, J.L. Sharks of the North American Waters. Texas A \& M University Press, 180 p., 1983.

Chaves, P.T.C. \& Robert, M.C. Embarcações, artes e procedimentos da pesca artesanal no litoral sul do estado do Paraná, Brasil. Atlântica, v. 25, n.1, p. 53-59, 2003.

Chaves, P.T.C. \& Silva, A.V.F. Recursos-alvo que são também bycatch, e recomendação para a gestão da pesca de emalhe no litoral do Paraná, Brasil. Revista CEPSUL - Biodiversidade e Conservação Marinha, v. 8, e2019001, 2019.

Compagno, L.J.V. FAO species catalogue, vol. 4, sharks of the world. An annotated and illustrated catalogue of shark species know to date. Part 2, Carcharhiniformes. FAO Fish. Synop, n. 125, v. 4, parte 2, p. 251-655, Roma, 1984.

Compagno, L.J.V. Checklist of living Chondrichthyes, p. 503-548, in Hamlett, W.C. (ed.). Reproductive biology and phylogeny of chondrichthyes: sharks, batoids and chimaeras. Enfield, Science Publishers, Inc., 2005.

Conrath, C.L. Reproductive Biology, in Musick, J.A. \& Bonfil, R. (ed.). Elasmobranch Fisheries Management Techniques. APEC Fisheries Working Group, p. 133-164, 2004.

Costa, L. \& Chaves, P.T.C. Elasmobrânquios capturados pela pesca artesanal na costa sul do Paraná e norte de Santa Catarina, Brasil. Biota Neotrop., v. 6, n. 3, bn02706032006, 2006.

Dias Neto, J. Proposta de plano de gestão para o uso sustentável de elasmobrânquios sobre-explotados ou ameaçados de sobre-explotação no Brasil. MMA, 154 p., Brasília, 2011.

Figueiredo, J.L. Manual de peixes marinhos do Sudeste do Brasil. Vol. 1, Introdução. Cações, raias e quimeras, Universidade de São Paulo, 104 p., São Paulo, 1977. 
Gadig, O.B. Tubarões da costa brasileira. Tese de doutorado, Ciências Biológicas - Zoologia, Universidade Estadual Paulista Júlio de Mesquita Filho, 291 p., Rio Claro, 2001.

Hoenig, J.M. \& Gruber, S.H. Life-history patterns in the elasmobranches: implications for fisheries management, p. 1-16, in Pratt, H.L.; Gruber, S.H. \& Taniuchi, T. (ed.), Elasmobranch as living resources: advances in biology, ecology and systematics, and the status of fisheries. NOAA Tecnichal Report NMFS 90, 1990.

Hubbs, C.L. \& Ishiyama, R. Methods for the taxonomic studies and description of skates (Rajidae). Copeia, v. 1968, n. 3, p. 483-491, 1968.

Lessa, R.; Santana, F.M.; Rincon, G.; Gadig, O.B.F. \& El-Deir, A.C.A. Biodiversidade de elasmobrânquios no Brasil, p. 303-307, in Biodiversidade Brasileira, MMA, 404 p., Brasília, 2002.

Lessa R.; Batista V.S. \& Santana F.M. Close to extinction? The collapse of the endemic daggernose shark (Isogomphodon oxyrhynchus) off Brazil. Global Ecology and Conservation, v. 7, p. 70-81, 2016.

Lorenzi, L. \& Borzone, C.A. Variabilidade da infauna adjacente a estruturas rochosas na plataforma rasa do litoral do Paraná, Brasil. Zoologia, Curitiba, v. 26, n. 4, 2009. doi. org/10.1590/S1984-46702009000400016.

Luiz, O.J. \& Edwards, A.J. Extinctionof a shark population in the Archipelago of Saint Paul's Rocks (equatorial Atlantic) inferred from the historical record. Biol. Cons., v. 144, n. 12, p. 2873-2881, 2011.

Martins, A.P.B.; Feitosa, L.M.; Lessa, R.P.; Almeida, Z.S.; Heupel, M.; Silva, W.M.; Tchaicka, L. \& Nunes, J.L.S. Analysis of the supply chain and conservation status of sharks (Elasmobranchii: Superorder Selachimorpha) based on fisher knowledge. PLoS ONE, v. 13, n. 3, p. 1-15, 2018.

Musick, J.A. \& Bonfil, R. Elasmobranch Fisheries Managmente Techniques. IUCN, APEC and VIMS, 370 p., Singapore, 2004.

Nunes, J.L.S.; Almeida, Z.S. \& Piorski, N.M. Raias capturadas pela pesca artesanal em águas rasas do Maranhão - Brasil. Arq. Ciên. Mar, Fortaleza, v. 38, p. 49-54, 2005.

Robert, M.C. \& Chaves, P.T.C. Dinâmica da atividade pesqueira artesanal em duas comunidades da região litorânea limítrofe Santa Catarina-Paraná, Brasil. Bol. Inst. Pesca, São Paulo, v. 32, n. 1, p. 15-23, 2006.

Shepherd, J.G. The Availability and Information of Fisheries Data, p. 95-109, in May, R.M. (ed.), Exploitation of Marine Communities, Springer-Verlag, 366 p., Berlin, 1984. 